\title{
Correction to: Nanotechnology and Diabetic Foot Ulcer: Future Prospects
}

Mohammad Azam Ansari, Khursheed Ali, Zeba Farooqui, Hanan A. Al-Dossary, Mohammad Zubair, and Javed Musarrat

\section{Correction to: \\ Chapter 20 in: Mohammad Zubair et. al., Diabetic Foot Ulcer: An Update, https://doi.org/10.1007/978-981-15-7639-3_20}

The book was inadvertently published with an incorrect spelling of the author's surname name in Chapter 20 as Mussart whereas it should be Musarrat. This error has now been corrected with this erratum. 